\title{
Influence of Geometry on the Stiffness of Corner Finger Joints
}

\author{
Gourav Kamboj, * Vladimír Záborský, and Tomáš Girl
}

\begin{abstract}
Finger joints enable the full utilization of wood. The finger joint technique is used to eliminate wood defects that would otherwise weaken the wood strength. This research project evaluated how the wood species, adhesive type, and number of teeth affect the elastic stiffness of finger joints. The adhesives used were polyurethane and polyvinyl acetate, and the wood species were beech (Fagus sylvatica L.) and spruce (Picea abies L.). This study also determined the elastic stiffness of finger joints with 2 teeth and 5 teeth. For this purpose, the samples were loaded via a bending moment reaction, with tensile or compression forces in the angular plane. The highest elastic stiffness was obtained from the beech wood samples with 5 teeth bonded with polyvinyl acetate adhesive under tensile stress. Therefore, it was concluded that the elastic stiffness increased when the number of teeth increased. However, further studies on the elastic stiffness of finger joints are necessary in relation to the finger teeth length and surface area of the glue between the finger joint connections.
\end{abstract}

Keywords: Wooden construction; Finger joint; Mechanical loading; Elastic deformation; Elastic stiffness

Contact information: Department of Wood Processing, Czech University of Life Sciences in Prague, Kamýcká 1176, Praha 6 - Suchdol, 16521 Czech Republic; *Corresponding author: kamboj@fld.czu.cz

\section{INTRODUCTION}

Joints fulfill important structural, technological, and operational-aesthetic functions in furniture construction. According to the available literature (Eckelman and Lin 1997; Smardzewski and Prekrad 2002; Eckelman 2003), joints in general are the weakest part of a given furniture piece; therefore, furniture durability depends on their quality. Structural design involves choosing the dimensions of load-bearing members and modelling the load-bearing structure according to the requirements set for the material resistance (Bustos et al. 2003; Crocetti et al. 2011).

Finger joints are commonly used to produce engineered wood products from short pieces of lumber. Such joints must have excellent mechanical performances. This jointing method is said to be an opportunity for mills to upgrade waste lumber and improve the return on low-grade lumber because of the considerably higher dimensional stability that occurs when drying shorter lumber, such as by delivering quasi-deliberate lengths and coping with decreasing log lengths in sawmills. Therefore, finger jointing is an ideal method for improving the efficiency and profitability of sawmills. Additionally, finger joints have been used for many years. In Canada and the USA, finger-jointed lumber is widely used for the fabrication of construction lumber or components of engineered wood products, such as a flange stock for a wood I-joist (Hernández et al. 2011). This joint is also used in the automotive industry for wooden steering wheels and wooden wheel 
spokes. Foremost, the application of finger jointing allows for the removal of strengthreducing defects.

Several researchers have investigated the effects of the glue line thickness on the strength of finger joints (Groom and Leichti 1994; River 1994). They found that it is necessary to control the glue line thickness to produce a strong joint. Using an increased glue area has produced a product with high engineering properties (Bustos et al. 2011). High strength finger joints require a maximized bonding surface area (Franke et al. 2014). An increase in the finger length resulted in an increase in bonding or contact with the finger surface. Ayarkwa et al. (2000) concluded that the effects of increased glue joint surface area also influenced the modulus of rupture of finger-jointed members. Polyurethane (PUR) adhesives provide interesting characteristics because they produce a high strength bond and cure at ambient conditions. Therefore, it was hypothesized that PUR adhesives are a viable alternative for wood finger joints (Verreault 1999; Chen and Walworth 2001; Lange et al. 2001). Murphey and Rishel (1972) explored the possibility of adopting finger jointing technology with polyvinyl acetate (PVAc) adhesive for use in furniture production, and it was found that such joints can replace mortise and tenon or dowel joints in furniture.

Finger joints have been shown to be suitable for use in connection with wood trusses, corner and multiple member furniture joints, laminated beams, and truck decking, as well as a variety of other structural and non-structural applications. Proof loading of end-jointed materials has been implemented in many instances to eliminate substandard joints. One aspect that is critical to the performance of finger joints during service is the overall geometry of the joint.

The purpose of this study was to compare the elastic stiffness of finger-jointed spruce and beech wood with either 2 teeth or 5 teeth and varying adhesive types (PUR or PVAc) under different loads (compression or tension). This study was the initial step to determine the elastic stiffness for different numbers of teeth in the finger jointing process, which will help the beech and spruce wood product industry to optimize their finger jointing methods.

\section{EXPERIMENTAL}

\section{Materials}

Beech (Fagus sylvatica L.) and spruce (Picea abies L.) lumber was used to produce test specimens. The lumber came from the woods near Spišska Nová Ves in Slovakia, which was where the basic test specimens were also prepared. The planks were first shortened for machining and then were thickened in a jointer and cut into precise 60$\mathrm{mm}(58-\mathrm{mm}) \times 20-\mathrm{mm}$ cross sections for the test specimens. The planks were then shortened to $215 \mathrm{~mm}$. The basic dimensions of the test specimens were $60 \mathrm{~mm}(58 \mathrm{~mm})$ $\times 20 \mathrm{~mm} \times 215 \mathrm{~mm}$, and there were 320 specimens. This was followed by milling of straight fingers using a planer milling machine (Profijoint, Grecon, Kopřivnice, Czech Republic). Either 2 teeth or 5 teeth were milled. Holes with a 10-mm diameter for subsequent fastening to the test machine were created using a rack drill. A diagram of the test specimens before gluing is shown in Fig. 1.

The joints were glued using two different adhesives, (PVAc) AG-COLL(EOC, Oudenaarde, Belgium) 8761/L D3 (EOC, Oudenaarde, Belgium) and (PUR) NEOPUR 
2238R (NEOFLEX, Madrid, Spain) . Detailed parameters of these adhesives are shown in Table 1. In both cases, the adhesive was applied to all of the joint surfaces using a brush and followed the curing conditions given in the technical data sheets. To achieve the required pressing pressure, a manual joiner brace was used. The test specimens were then allowed to harden.
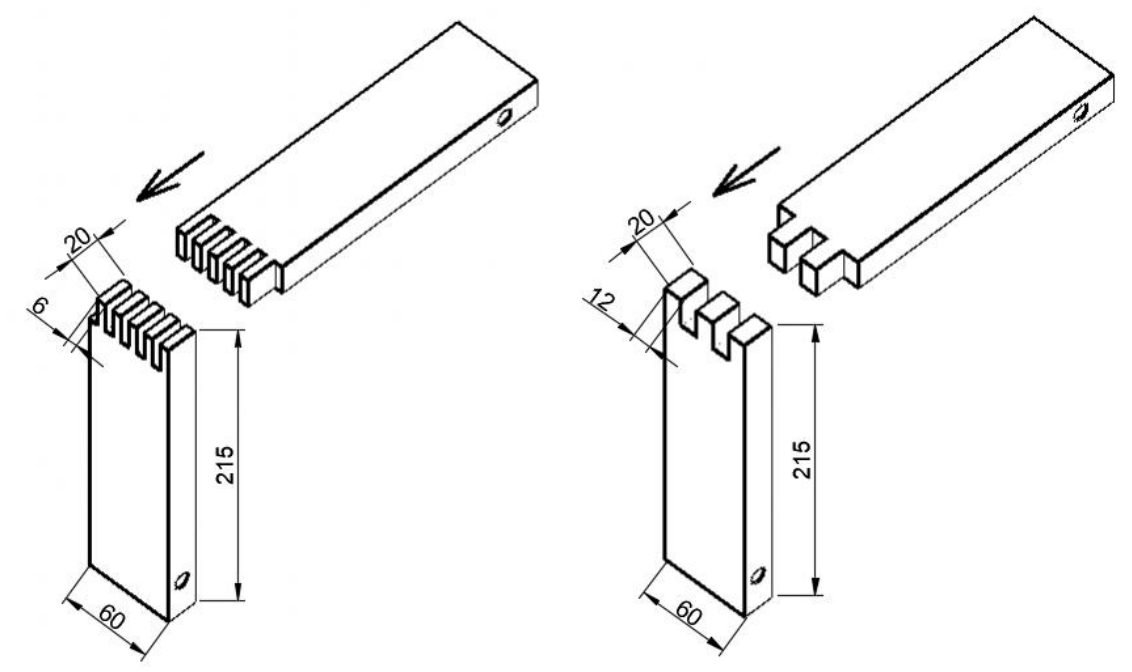

Fig. 1. Dimension of the test specimens

The glued specimens were placed in a climatic chamber that was set to a temperature of $20{ }^{\circ} \mathrm{C}\left( \pm 2{ }^{\circ} \mathrm{C}\right)$ and humidity of $55 \%( \pm 5 \%)$, so that the final moisture content of the material was 10\%, as was established by ČSN EN 942 (2007) for wood used inside heated buildings.

Table 1. Parameters of the PVAc and PUR Adhesives

\begin{tabular}{|c|c|c|}
\hline Technical Data for Adhesive & AG-COLL $8761 / \mathrm{L}$ D3 & NEOPUR 2238R \\
\hline Viscosity (mPa) & 5000 to 7000 at $23^{\circ} \mathrm{C}$ & 2000 to 4500 at $25^{\circ} \mathrm{C}$ \\
\hline Working time $(\mathrm{min})$ & 15 to 20 & 60 \\
\hline Density $(\mathrm{g} / \mathrm{cm} 3)$ & 0.9 to 1.1 at $23^{\circ} \mathrm{C}$ & ca. 1.13 \\
\hline NCO content $(\%)$ & - & ca. 15.5 to 16.5 \\
\hline Color & White, milky & Brown \\
\hline Open time $(\mathrm{min})$ & 15 & ca. 20 to 25 \\
\hline Dry matter content $(\mathrm{g})$ & 49 to 51 & 100 \\
\hline $\mathrm{pH}$ & to 4.5 & - \\
\hline
\end{tabular}

\section{Methods}

The climatized specimens were subjected to strength tests. The specimens were loaded with compression or tensile stress in the angular plane, as is shown in Fig. 2. 


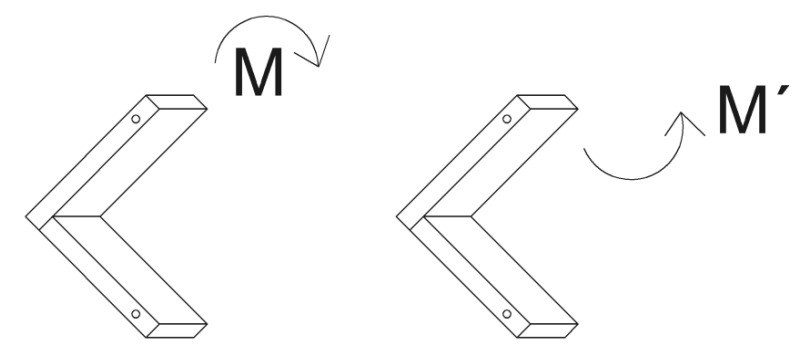

Fig. 2. Test specimen loading

The testing was performed on a UTS 50 universal testing machine (TIRA, Germany), which was designed for testing the mechanical properties of wood and woodbased materials. The values were recorded by the TIRA program (TIRA System GmbH, Schalkau, Germany). This program was also used to set the loading speed so that the test was performed properly according to the $90-\mathrm{s}$ ( $\pm 30 \mathrm{~s}$ ) standard. The loading speed ranged from $9 \mathrm{~mm} / \mathrm{min}$ to $12 \mathrm{~mm} / \mathrm{min}$. The machine recorded the applied force and load head displacement. It also recorded the tests graphically and numerically. To clamp the specimens into the testing machine, a clamping tool was used according to the methodology by Podlena and Borůvka (2016), which they used to test window frames. Each specimen was weighed and recorded with a digital scale after testing.

The monitored factors (F1 through F4) are given in Table 2. The test specimens were divided into 16 sets, according to the individual parameters, and the effects of the individual factors on the stiffness of the joints were monitored. Each set contained 20 test specimens.

Table 2. Categorization of the Observed Factors of the Test Samples

\begin{tabular}{|c|c|c|c|}
\hline \multicolumn{2}{|c|}{ Factor $1-$ Wood Species } & \multicolumn{2}{|c|}{ Factor $2-$ Type of Glue } \\
\hline Beech & Spruce & PVAC & PUR \\
\hline \multicolumn{2}{|c|}{ Factor $3-$ Number of Teeth } & \multicolumn{2}{|c|}{ Factor $4-$ Type of Loading } \\
\hline 2 & 5 & Tension $(\leftarrow \rightarrow)$ & Compression $(\rightarrow \leftarrow)$ \\
\hline
\end{tabular}

A bending moment was generated in a specimen during loading and the test continued until the specimen broke. The bending moment was used to calculate the elastic stiffness, and the stiffness at the maximum load was calculated using the following equations (Eqs. 1 to 3). The output of the test was a stress-strain diagram with data on the dependence between the force and resulting deformation (load head displacement). The force and deformation at $10 \%$ and $40 \%$ of the yield strength of the joint were also recorded.

The essential characteristics of the wood include the density at a given moisture content, which was determined according to ISO 13061-1 (2014). The density was calculated for the entire specimen together. After testing, the density was immediately determined for the entire specimen at a given moisture content in accordance with ČSN 490108 (1993), using Eq. 1,

$$
\rho_{\mathrm{w}}=\frac{m_{\mathrm{w}}}{V_{\mathrm{w}}}
$$


where $\rho_{\mathrm{w}}$ is the density $\left(\mathrm{kg} \cdot \mathrm{m}^{-3}\right)$ at the given moisture content $w(\%), m_{\mathrm{w}}$ is the weight $(\mathrm{kg})$ at the given moisture content $w$, and $V_{\mathrm{w}}$ is the volume of the specimen $\left(\mathrm{m}^{3}\right)$ at the given moisture content $w$.

The moisture content $(w)$ of the climatized specimens was determined in accordance with ČSN 490103 (1979), using Eq. 2,

$$
w=\frac{m_{w}-m_{0}}{m_{0}} \times 100 \%
$$

where $m_{0}$ is the mass (weight) of oven-dry sample $(\mathrm{kg})$.

To calculate the bending moment induced in the test specimen, the length of the arm (Fig. 3) needed to be determined, which was done using Eq. 3,

$$
l_{0}=a \cos 45
$$

where $l_{0}$ is the length of the arm (m) and $a$ is the length of the hypotenuse of the right triangle formed $(\mathrm{m})$.

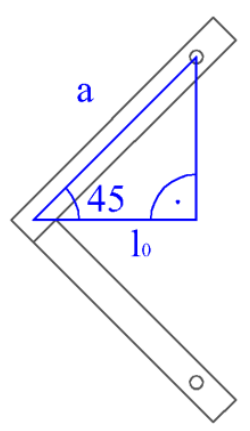

Fig. 3. Scheme of the length calculation and 5 ,

The bending moment induced in the specimen was calculated according to Eqs. 4

$$
\begin{aligned}
& M=F l_{0} \\
& \Delta M=\Delta F l_{0}
\end{aligned}
$$

where $F$ is the maximum applied force $(\mathrm{N}), M$ is the maximum bending moment $(\mathrm{Nm})$ at the maximum load $F, \Delta F$ is the difference in the forces $(\mathrm{N})$ for the $10 \%$ and $40 \%$ loads, $\Delta M$ is the difference in the moments $(\mathrm{Nm})$ for the $10 \%$ and $40 \%$ loads, and $l_{0}$ represents the force applied to the vertical arm of tested joints.

The force applied to a specimen caused it to deform to $L^{\prime}$. Tensile stress causes it to elongate, and compression stress causes the specimen to shorten. Diagrams of the deformation of the specimens are shown in Fig. 4. 


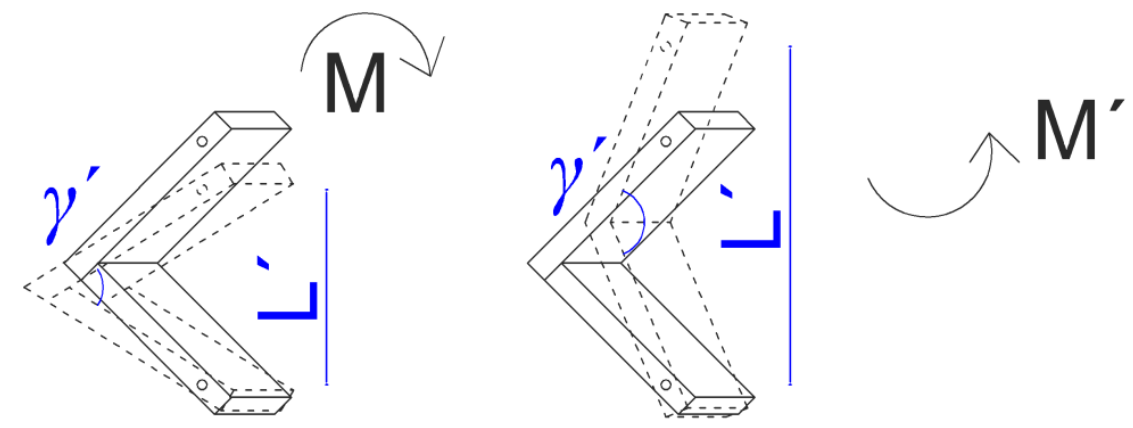

Fig. 4. Deformation of the test samples during loading

If there is a change in angle $\left(\gamma^{\prime}\right)$, which clasps the arms of the test specimen, this change can be calculated in radians according to Eq. 6 ,

$$
\gamma^{\prime}=2 \arcsin \frac{L^{\prime}}{2 a}
$$

where $\gamma^{\prime}$ is the size of the angle (rad) that is clasping the arms of the test specimen after loading and $L^{\prime}$ is as the length of the support span (m) when the force is applied.

The size of this angle was expressed according to Eq. 7,

$$
\pi \mathrm{rad}=180^{\circ}
$$

The difference in these angles was used to calculate angular displacement according to Eq. 8,

$$
\Delta \gamma=90 \pm \gamma^{\prime}
$$

Stiffness is the resistance of a structure to deformation (Joščák et al. 2015), and it was calculated as the ratio of the bending moment to the angle change caused by this moment, as shown by Eqs. 9 and 10,

$$
\begin{aligned}
& C_{\max }=\frac{M_{\max }}{\gamma_{\max }} \\
& C_{\text {elast }}=\frac{\Delta M}{\Delta y}
\end{aligned}
$$

where $C_{\max }$ is the maximum stiffness of the joint $(\mathrm{Nm} / \mathrm{rad}), M_{\max }$ is the maximum bending moment $(\mathrm{Nm}), \gamma_{\max }$ is the angle (rad) caused by $M_{\max }, C_{\text {elast }}$ is the stiffness of the joint in the elastic region $(\mathrm{Nm} / \mathrm{rad}), \Delta M$ is the difference in the moments $(\mathrm{Nm})$ at the $10 \%$ and $40 \%$ loads, and $\Delta \gamma$ is the change in the angles (rad) at the $10 \%$ and $40 \%$ loads.

\section{RESULTS AND DISCUSSION}

The highest elastic stiffness was obtained with 5 teeth joint of beech wood (3254 $\mathrm{Nm} / \mathrm{rad}$ ) bonded with PVAc adhesive under tensile load, and the lowest elastic stiffness was found with 2 teeth joint of spruce wood (1279 Nm/rad) bonded with PVAc adhesive under compression load. The data for the beech and spruce wood samples with different numbers of teeth, load types, and adhesive types is shown in Table 3. 
Table 3. Density and Stiffness for the Individual Sample Sets

\begin{tabular}{|l|c|c|c|c|c|c|}
\hline $\begin{array}{c}\text { Wood } \\
\text { Species }\end{array}$ & Adhesive Type & Number of Teeth & Type of Loading & $\begin{array}{c}\text { Density } \\
\left(\mathrm{g} / \mathrm{cm}^{3}\right)\end{array}$ & $\begin{array}{c}\text { Elastic Stiffness } \\
(\mathrm{Nm} / \mathrm{rad})\end{array}$ & $N$ \\
\hline Spruce & PVAC & 2 & Compression & $378(7.7)$ & $1279(15.6)$ & 20 \\
\hline Spruce & PVAC & 2 & Tension & $355(4.6)$ & $1495(11.1)$ & 20 \\
\hline Spruce & PVAC & 5 & Compression & $376(7.8)$ & $2057(17.4)$ & 20 \\
\hline Spruce & PVAC & 5 & Tension & $376(5.5)$ & $1863(19.6)$ & 20 \\
\hline Spruce & PUR & 2 & Tension & $369(7.3)$ & $1454(19.3)$ & 20 \\
\hline Spruce & PUR & 2 & Compression & $378(6.5)$ & $1416(19.4)$ & 20 \\
\hline Spruce & PUR & 5 & Compression & $394(7.4)$ & $1977(13.3)$ & 20 \\
\hline Spruce & PUR & 5 & Tension & $416(8.6)$ & $2096(14.5)$ & 20 \\
\hline Beech & PVAC & 2 & Compression & $688(4.6)$ & $2463(14.2)$ & 20 \\
\hline Beech & PVAC & 2 & Tension & $678(3.8)$ & $2511(17.4)$ & 20 \\
\hline Beech & PVAC & 5 & Compression & $679(6.2)$ & $3150(18.2)$ & 20 \\
\hline Beech & PVAC & 5 & Tension & $667(5.3)$ & $3254(16.4)$ & 20 \\
\hline Beech & PUR & 2 & Compression & $731(4.1)$ & $2456(17.2)$ & 20 \\
\hline Beech & PUR & 2 & Tension & $670(5.5)$ & $2617(18.4)$ & 20 \\
\hline Beech & PUR & 5 & Compression & $644(6.2)$ & $2996(19.2)$ & 20 \\
\hline Beech & PUR & 5 & Tension & $650(7.3)$ & $3083(11.4)$ & 20 \\
\hline
\end{tabular}

Values in parentheses are coefficients of variation (CV) in \%.

Table 4 shows the results of the four-factor analysis of variance (ANOVA) and Fisher's F-Test with STATSTICA 12 software (Statsoft Inc; Oklahoma, USA) that evaluated the influence of individual factors on the joint stiffness and the interaction of all of the factors together (F1 through F4). It was clear from the $P$-values that the wood species, number of teeth, and loading type were statistically significant factors for the one-factor analysis. The effect of the adhesive type by itself was not significant, but in combination with the other factors, its effect was significant. The four-factor analysis revealed the statistical significance of the interaction of the monitored characteristics.

Table 4. Statistical Evaluation of the Factors Influencing the Elastic Stiffness

\begin{tabular}{|c|c|c|c|c|c|}
\hline Monitored Factor & $\begin{array}{c}\text { Sum of } \\
\text { Squares }\end{array}$ & $\begin{array}{c}\text { Degree of } \\
\text { Freedom }\end{array}$ & Variance & Fisher's F-test & $\begin{array}{c}\text { Significance } \\
P \text {-value }\end{array}$ \\
\hline Intercept & 817521787 & 1 & 817521787 & 18142.56 & ${ }^{* * *}$ \\
\hline 1) Wood Species & 49457268 & 1 & 49457268 & 1097.56 & ${ }^{* * *}$ \\
\hline 2) Adhesive Type & 329 & 1 & 329 & 0.01 & $N S$ \\
\hline $\begin{array}{c}\text { 3) Number of } \\
\text { Teeth }\end{array}$ & 14307412 & 1 & 14307412 & 317.51 & ${ }^{* * *}$ \\
\hline $\begin{array}{c}\text { 4) Type of } \\
\text { Loading }\end{array}$ & 209710 & 1 & 209710 & 4.65 & ${ }^{* * *}$ \\
\hline $1^{*} 2^{*} 4$ & 242470 & 1 & 242470 & 5.38 & ${ }^{* * *}$ \\
\hline Error & 6488781 & 144 & 45061 & & \\
\hline
\end{tabular}

The respective model explains roughly $69.9 \%$ of the total sum of squares; NS - not significant, *** - significant; significance was accepted at $P<0.05$ 
The wood species had an effect on the elastic stiffness, and on average, the beech joint exhibited a $65 \%$ greater elastic stiffness than the spruce joint (Fig. 5A). This also demonstrated the higher elasticity obtained from the beech wood samples bonded with the PVAc adhesive (Özçifçi and Yapıcı 2008). The elastic stiffness of the joints bonded with the PUR adhesive was $0.12 \%$ higher than that of the joints bonded with the PVAc adhesive (Fig. 5B). Záborský et al. (2018) found that there was also a small difference in the bonding factor for dowel joints.

Figure 5C shows the influence of the number of teeth on the elastic stiffness. The 5-tooth joints exhibited a $30.4 \%$ higher elastic stiffness than the 2-tooth joints. This meant that the elastic stiffness increased with an increase in the number of teeth in the finger joint. This result corresponded to the results of other researchers (Selbo 1963; Bustos et al. 2011; Franke et al. 2014). The test specimens subjected to tensile stress exhibited a $3.27 \%$ greater elastic stiffness on average than the specimens subjected to compression stress (Fig. 5D).

Figure 6 illustrates the effective interaction of the individual factors on the elastic stiffness with a particular effect from the wood species, adhesive type, number of teeth, and load type. Under compression stress, the elastic stiffness of the spruce wood was 49.7\% higher with a 5-tooth joint when compared with a 2-tooth joint (Fig. 6), while a $25 \%$ higher elastic stiffness was found for the beech wood. When comparing the elastic stiffness of 5 tooth joint of spruce wood, it was found that the elastic stiffness of joints bonded with PVAc adhesive was $4.04 \%$ higher than the elastic stiffness of PUR adhesive with the same type of joints. In contrast, when subjected 2 tooth joints with spruce wood, the type of the joint exhibited higher elastic stiffness bonded with PUR adhesive; the values were $10.7 \%$ higher than bonded with PVAc adhesive with the same type of joint.

(A)

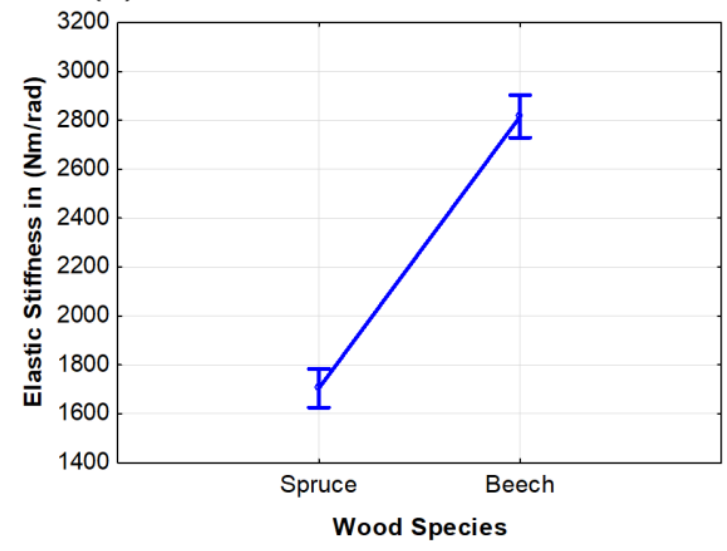

(B)

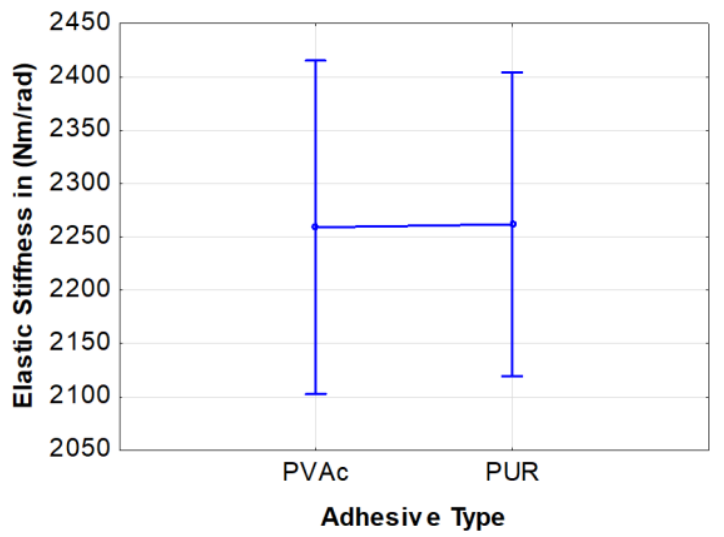



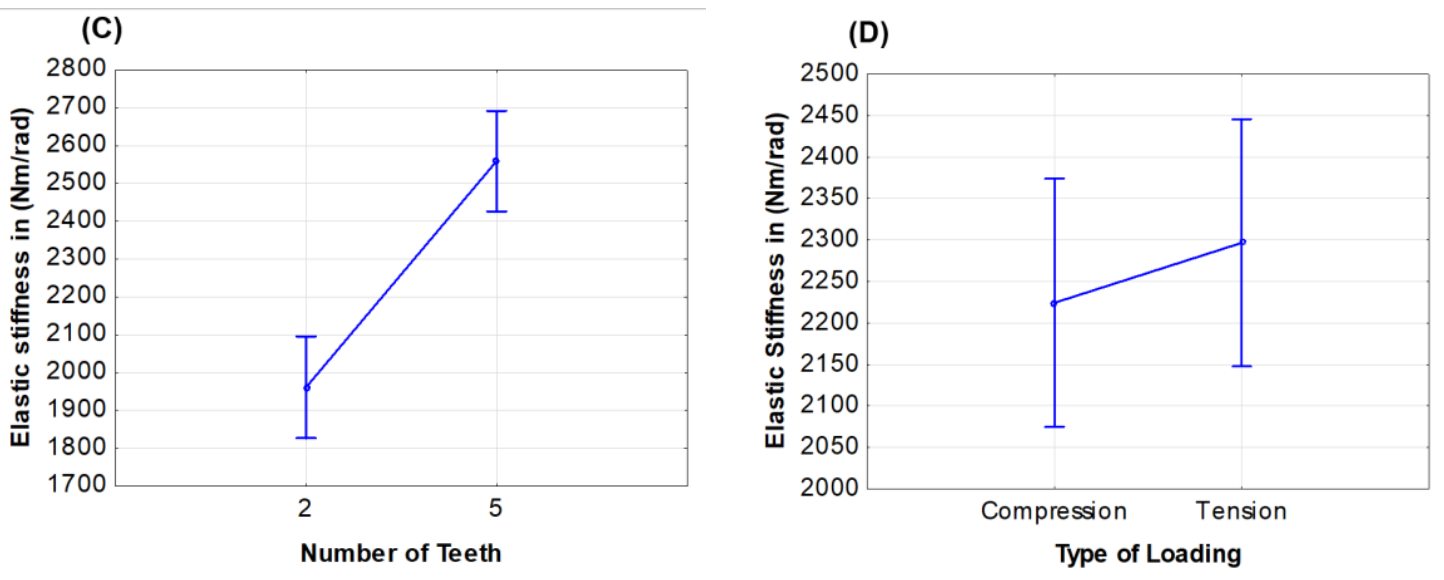

Fig. 5. Graphic visualization of the effect of the wood species (A), adhesive (B), number of teeth (C), and loading (D) on the elastic stiffness

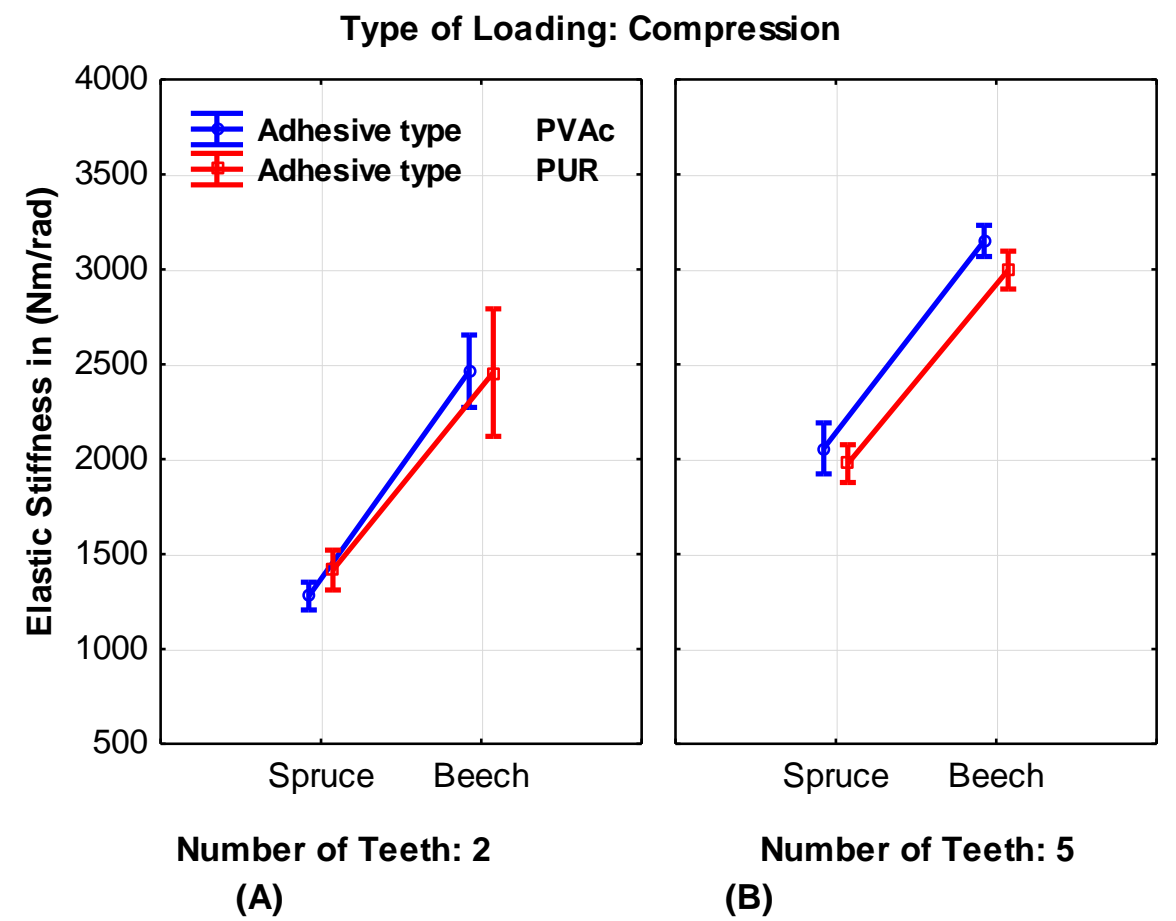

Fig. 6. Graphic visualization of the influence of the wood species and adhesive type on the elastic stiffness while under compression stress for (A) 2 teeth and (B) 5 teeth

Another finding was that the elastic stiffness of beech wood with 5 tooth joints, bonded with PVAc adhesive was 5.14\% higher than the elastic stiffness of joint bonded with PUR adhesive with the same type of joints (these results were notably demonstrated in joints subjected to compressive stress).

When placed under tensile stress, the elastic stiffness of the spruce wood was $34.2 \%$ higher with 5 teeth than with 2 teeth (Fig. 7). The elastic stiffness of the beech wood was nearly $24 \%$ higher with 5 teeth compared with 2 teeth, under both stresses (compression and tensile). The adhesives used in this study had a slight effect on the elastic stiffness. Hemmasi et al. (2014) found in previous studies concerning a $10-\mathrm{mm}$ 
oak wood finger joint that the PVAc adhesive did not cause any serious change in the studied elastic properties of the beams. Under tensile load, the elastic stiffness of 5 teeth joints have interesting results. In case of spruce wood, the elastic stiffness of joints bonded with PUR was $12 \%$ higher than the joints bonded with PVAc adhesive. On the other side, the trend was opposite in beech wood; the elastic stiffness of joints bonded by PVAc adhesive was $5.7 \%$ higher value than the joints bonded with PUR adhesive. The elastic stiffness of 2 teeth joints of spruce wood bonded with PVAc obtained $2.8 \%$ higher elastic stiffness than joints bonded with PUR adhesive and in beech wood, the results showed that joints bonded with PUR obtained $4.22 \%$ higher elastic stiffness than joints bonded with PVAc.

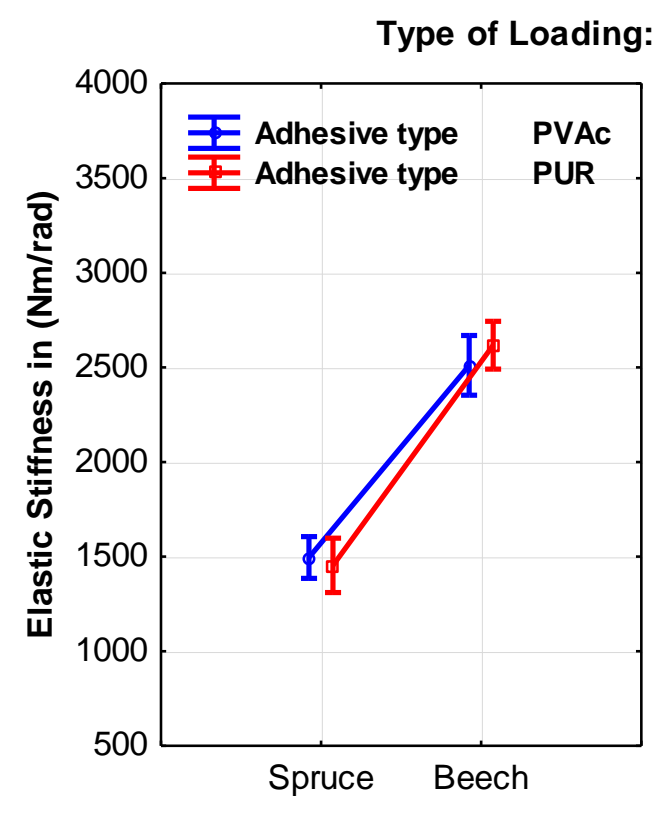

Number of Teeth: 2

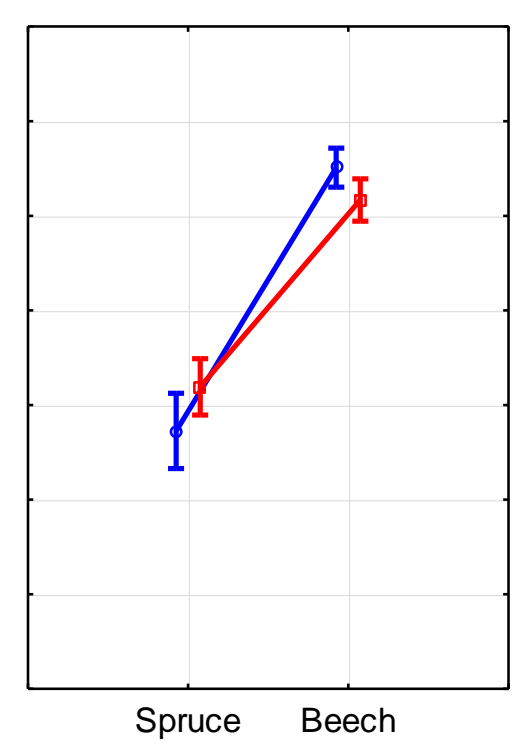

Number of Teeth: 5

Fig. 7. Graphic visualization of the influence of the wood species and adhesive type on the elastic stiffness while under tensile stress for (A) 2 and (B) 5 teeth

Duncan's test made multiple comparisons of all 16 test sample sets against each other. The results followed the data from the ANOVA test. The results of the tests that were conducted to determine the importance of the difference between the groups are shown in Table 5. 
Table 5. Multiple Comparison of the Elastic Stiffness using Duncan's Test

\begin{tabular}{|c|c|c|c|c|c|c|c|c|c|c|c|c|c|c|c|c|c|c|}
\hline $\begin{array}{c}\text { Adhesive } \\
\text { Type }\end{array}$ & $\begin{array}{l}\text { No. } \\
\text { of } \\
\text { Teeth }\end{array}$ & $\begin{array}{l}\text { Type of } \\
\text { Loading }\end{array}$ & $\begin{array}{c}(1) \\
1279\end{array}$ & $\begin{array}{c}(2) \\
1495\end{array}$ & $\begin{array}{c}(3) \\
2057\end{array}$ & $\begin{array}{c}(4) \\
1863\end{array}$ & $\begin{array}{c}(5) \\
1415\end{array}$ & $\begin{array}{c}(6) \\
1416\end{array}$ & $\begin{array}{c}(7) \\
1977\end{array}$ & $\begin{array}{c}(8) \\
2095.8\end{array}$ & $\begin{array}{c}(9) \\
2463\end{array}$ & $\begin{array}{l}(10) \\
2510\end{array}$ & $\begin{array}{c}(11) \\
3149\end{array}$ & $\begin{array}{c}(12) \\
3254\end{array}$ & $\begin{array}{c}(13) \\
2456\end{array}$ & $\begin{array}{l}(14) \\
2617\end{array}$ & $\begin{array}{c}(15) \\
2996\end{array}$ & $\begin{array}{c}(16) \\
3083\end{array}$ \\
\hline PVAC & 2 & Compression & & & & & & & & & & & & & & & & \\
\hline PVAC & 2 & Tension & 0.035 & & & & & & & & & & & & & & & \\
\hline PVAC & 5 & Compression & 0.000 & 0.000 & & & & & & & & & & & & & & \\
\hline PVAC & 5 & Tension & 0.000 & 0.000 & 0.052 & & & & & & & & & & & & & \\
\hline PUR & 2 & Compression & 0.149 & 0.434 & 0.000 & 0.000 & & & & & & & & & & & & \\
\hline PUR & 2 & Tension & 0.081 & 0.660 & 0.000 & 0.000 & 0.690 & & & & & & & & & & & \\
\hline PUR & 5 & Compression & 0.000 & 0.000 & 0.397 & 0.231 & 0.000 & 0.000 & & & & & & & & & & \\
\hline PUR & 5 & Tension & 0.000 & 0.000 & 0.683 & 0.023 & 0.000 & 0.000 & 0.239 & & & & & & & & & \\
\hline PVAC & 2 & Compression & 0.000 & 0.000 & 0.000 & 0.000 & 0.000 & 0.000 & 0.000 & 0.000 & & & & & & & & \\
\hline PVAC & 2 & Tension & 0.000 & 0.000 & 0.000 & 0.000 & 0.000 & 0.000 & 0.000 & 0.000 & 0.618 & & & & & & & \\
\hline PVAC & 5 & Compression & 0.000 & 0.000 & 0.000 & 0.000 & 0.000 & 0.000 & 0.000 & 0.000 & 0.000 & 0.000 & & & & & & \\
\hline PVAC & 5 & Tension & 0.000 & 0.000 & 0.000 & 0.000 & 0.000 & 0.000 & 0.000 & 0.000 & 0.000 & 0.000 & 0.272 & & & & & \\
\hline PUR & 2 & Compression & 0.000 & 0.000 & 0.000 & 0.000 & 0.000 & 0.000 & 0.000 & 0.000 & 0.941 & 0.593 & 0.000 & 0.000 & & & & \\
\hline PUR & 2 & Tension & 0.000 & 0.000 & 0.000 & 0.000 & 0.000 & 0.000 & 0.000 & 0.000 & 0.126 & 0.262 & 0.000 & 0.000 & 0.123 & & & \\
\hline PUR & 5 & Compression & 0.000 & 0.000 & 0.000 & 0.000 & 0.000 & 0.000 & 0.000 & 0.000 & 0.000 & 0.000 & 0.127 & 0.011 & 0.000 & 0.000 & & \\
\hline PUR & 5 & Tension & 0.000 & 0.000 & 0.000 & 0.000 & 0.000 & 0.000 & 0.000 & 0.000 & 0.000 & 0.000 & 0.484 & 0.089 & 0.000 & 0.000 & 0.358 & \\
\hline
\end{tabular}




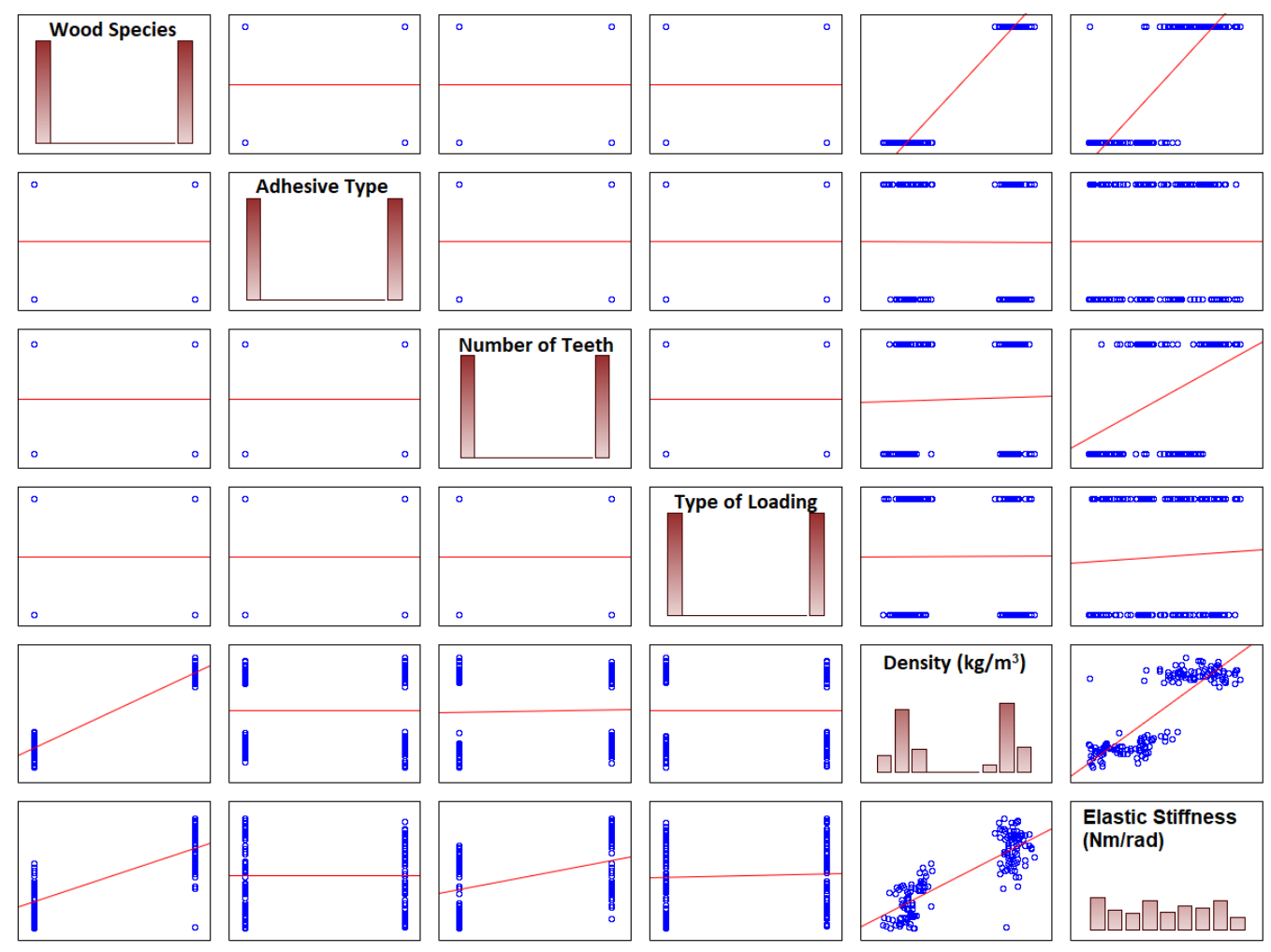

Fig. 8. Graphic visualization of Spearman's rank-correlation test 
According to Duncan's test, when considering the interactions between the joint and stress type, the highest elastic stiffness was obtained from the beech wood sample with 5 teeth. Beech wood also has a fine tight grain, large medullary rays, and a small tracheal structure. This may have been a result of the beech wood density because Örs $e t$ al. (2004) reported that the high density of beech wood $\left(0.67 \mathrm{~g} / \mathrm{cm}^{3}\right)$ increased its mechanical properties

The results of the correlation analysis (Fig. 8) showed how the individual characteristics affected each other. The elastic stiffness was highly correlated with the wood species, wood density, and number of teeth in the finger joints. There was also a slight correlation with the loading type within the experiment.

\section{CONCLUSIONS}

1. For the elastic stiffness, the number of teeth in the finger joint played a significant role and increasing the number of teeth increased the elastic stiffness. In general, the elastic stiffness of the 5-tooth joints was $30.4 \%$ higher than that of the 2-tooth joints.

2. Comparing the elastic stiffness of the wood species, the spruce wood had a large variation in the elastic stiffness under both stress types with 2 teeth and 5 teeth, while the beech wood had nearly the same difference in the elastic stiffness.

3. Both of the adhesives (PUR and PVAc) proved to be nearly equivalent in finger jointing ( 2 teeth and 5 teeth) for both wood species (spruce and beech). The elastic stiffness test results suggested that the PUR adhesive formed a high-quality bond.

\section{ACKNOWLEDGMENTS}

The authors are grateful for the support of the project "Advanced research supporting the forestry and wood-processing sector's adaptation to global change and the $4^{\text {th }}$ industrial revolution" (No. CZ.02.1.01/0.0/0.0/16_019/0000803) financed by OP RDE and for the support of the University Internal Grant Agency (IGA) of the Faculty of Forestry and Wood Sciences (Project No. 43230 / 1312 / 3168).

\section{REFERENCE CITED}

Ayarkwa, J., Hirashima, Y., and Sasaki, Y. (2000). "Effect of finger geometry and end pressure on the flexural properties of finger-jointed tropical African hardwoods," Forest Prod. J. 50(11-12), 53-63.

Bustos, C., Beauregard, R., Mohammad, M., and Hernández, R. E. (2003). "Structural performance of finger-jointed black spruce lumber with different joint configurations," Forest Prod. J. 53(9), 72-76.

Bustos, C., Hernández, H., Beauregard, R. E., and Mohammad, M. (2011). "Effect of end-pressure on the finger-joint quality of black spruce lumber: A microscopic analysis," Maderas-Cienc. Tecnol. 13(3), 319-328. DOI: 10.4067/S0718221X2011000300007 
Chen, G.-F., and Walworth, G. (2001). "Two-part polyurethane adhesive for structural finger joints," U. S. Patent No. 7655312B2.

Crocetti, R., Johansson, M., Johnsson, H., Kliger, R., Mårtensson, A., Norlin, B., Pousette, A., and Thelandersson, S. (2011). Design of Timber Structures, Swedish Wood, Malmö, Sweden.

ČSN EN 942 (2007). "Timber in joinery - General requirements," Czech Office for Standards, Metrology and Testing, Prague, Czech Republic.

ČSN 490108 (1993). "Wood - Density detection," Czech Office for Standards, Metrology and Testing, Prague, Czech Republic.

ČSN 490103 (1979). "Wood - Moisture detection in physical and mechanical tests," Czech Office for Standards, Metrology and Testing, Prague, Czech Republic.

Eckelman, C. A. (2003). Textbook of Product Engineering and Strength Design of Furniture, Purdue University, West Lafayette, Indiana.

Eckelman, C. A., and Lin, F. C. (1997). "Bending strength of corner joints constructed with injection-molded splines," Forest Prod. J. 47(4), 89-92.

Franke, B., Schusser, A., and Müller, A. (2014). "Analysis of finger joints from beech wood," in: World Conference on Timber Engineering, Quebec, Canada.

Hemmasi, A. H., Khademi-Eslam, H., Roohnia, M., Bazyar, B., and Yavari, A. (2014). "Elastic properties of oak wood finger joints with polyvinyl acetate and isocyanate adhesives," BioResources 9(1), 849-860. DOI: 10.15376/biores.9.1.849-860

Hernández, R. E., Coman, R., and Beauregard, R. (2011). "Influence of machining parameters on the tensile strength of finger-jointed high-density black spruce lumber," Wood Sci. Technol. 43(1), 2-10.

ISO 13061-1 (2014). "Physical and mechanical properties of wood - Test method for small clear wood specimens - Part 1: Determination of moisture content for physical and mechanical tests," International Organization for Standardization, Geneva, Switzerland.

Joščák, P., Langová, N., and Krasula, P. (2015). Mechanické Skúšky Nábytku [Mechanical Tests of Furniture], Technical University in Zvolen, Zvolen, Slovakia.

Lange, D. A., Fields, J. T., and Stirn, S. A. (2001). "Finger joint application potentials for one-part polyurethanes," in: Proceedings of the Wood Adhesives 2000 Symposium, Madison, WI, pp. 17-18.

Murphey, W. K., and Rishel, L. E. (1972). "Finger joint feasibility in furniture production," Forest Prod. J. 22(2), 30-32.

Örs, Y., Atar, M., and Keskin, H. (2004). "Bonding strength of adhesive in wood materials impregnated with Imersol-Aqua," Int. J. Adhes. Adhes. 24(4), 287-294. DOI: 10.1016/j.ijadhadh.2003.10.007

Özçifçi, A., and Yapıc1, F. (2008). "Structural performance of the finger-jointed strength of some wood species with different joint configurations," Constr. Build. Mater. 22(7), 1543-1550. DOI: 10.1016/j.conbuildmat.2007.03.020

Podlena, M., and Borůvka, V. (2016). "Stiffness coefficients of mortise and tenon joints used on wooden window profile," BioResources 11(2), 4677-4687. DOI: 10.15376/biores.11.2.4677-4687

River, B. (1994). "Fracture of adhesive-bonded wood joints," in: Handbook of Adhesive Technology, Revised and Expanded, A. Pizzi and K. L. Mittal (eds.), CRC Press, Boca Raton, FL, pp. 325-350. 
Selbo, M. L. (1963). "Effect of joint geometry on tensile strength of finger joints," Forest Prod. J. 13(9), 390-400.

Smardzewski, J., and Prekrad, S. (2002). "Stress distribution in disconnected furniture joints," Electronic Journal of Polish Agricultural University 5(2), 1-7. ISSN: 15050297

Verreault, C. (1999). Performance Evaluation of Green Gluing for Finger Jointing (Report No. 2295), Forintek Canada Corporation, Quebec, Canada.

Záborský, V., Sikora, A., Gaff, M., Kašíčková, V., and Borůvka, V. (2018). "Effect of selected factors on stiffness of dowel joints," BioResources 13(3), 5416-5431. DOI: 10.15376/biores.13.3.5416-5431

Article submitted: October 9, 2018; Peer review completed: January 13, 2019; Revised version received: January 29, 2019; Accepted: February 5, 2019; Published: February 25, 2019.

DOI: 10.15376/biores.14.2.2946-2960 